Studies EAJMBS October - December 2021, Vol. 1, No. 1, pp. 1-7

\title{
Challenges Faced By Ward Officers in Practicing Accountability and Participation: A Case of Arusha City, Tanzania
}

\author{
Monica Augustin Mshanga* \\ ORCID: 0000-0002-0742-7766 \\ Department of Postgraduate Studies \\ Institute of Accountancy Arusha, Tanzania \\ Gloria Reverian Kimburu \\ ORCID: 0000-0002-1047-9671 \\ Department of Postgraduate Studies \\ Institute of Accountancy Arusha, Tanzania \\ *Corresponding Mail: monicmshanga@gmail.com

\begin{abstract}
Copyright resides with the author(s) in terms of the Creative Commons Attribution CC BY-NC 4.0. The users may copy, distribute, transmit and adapt the work, but must recognize the author(s) and the East African Journal of Management and Business Studies
\end{abstract}

\begin{abstract}
This study observed challenges faced by Ward Officers (WOs) in practicing accountability and participation in the wards in Arusha city. The study adopted descriptive research design and used mixed method research approach. The population involved 175 ward officers in 25 wards in Arusha city from which a sample of 70 ward officers was drawn, but only 68 (97\%) of them participated. Purposive sampling and simple random technique were used to obtain respondents. Data was collected through questionnaires and interview guide. Quantitative data were analysed using descriptive statistics, while qualitative data were subjected to thematic analysis. Findings revealed that challenges faced by WOs in practicing accountability and participation in their wards includes: little turn up of citizens in political election, lack of interests to participate in decision making, misuse of resources and environmental pollution, corruption and insufficient funds. The study recommended that local government authorities should educate its people on the importance of participating on different development activities from planning to implementation, and WOs should ensure ward information are accessible by the public.
\end{abstract}

Keywords: Ward Officer, accountability, participation, Arusha, Tanzania

How to cite: Mshanga, M. A., and Kimburu, G, R. (2021). Challenges Faced By Ward Officers in Practicing Accountability and Participation: A Case of Arusha City, Tanzania. East African Journal of Management and Business Studies 1(1), 1-7. Doi: https://doi.org/10.46606/eajmbs2021v01i01.0001

\section{Introduction}

The concept of governance is as old as the governance itself. This concept has gained popularity recently and has become buzzword in the politics and administrative reforms. Good Governance denotes a participatory approach of governing that functions in a transparent, responsible and accountable way based on the principles of efficiency, legitimacy and consensus. The aim of good governance in the public sector is to promote enhanced service delivery in addition to improved accountability through establishment of criterion for good governance (Ekundayo, 2017). Effective governance in the public sector improves decision making and proficient use of resources in addition to strengthening accountability (Mutahaba, 2012).

Poor governance is one of the core causes of all evils and sufferings within our societies, including the local governments in Tanzania. Wakasangula (2017) argues that poor governance practices in Tanzanian local governments is the complete opposite of good 
governance and involves abuse of human rights, corruption, lack of transparency, lack of responsiveness and lack of accountability.

In an attempt to stop bad governance in local governments, the government of Tanzania has formulated a policy framework for development and poverty reduction that emphasizes on good governance along with the growing economy. This framework includes the Tanzania Development Vision (TDV) 2025 and the policy framework for development and poverty reduction (Mdee \& Thorley, 2016). These programs comprise the policy and strategic framework for boosting accountability and transparency in addition to integrity in the use of public resources and to improve service (Mdee \& Thorley, 2016). One of the objectives of the establishment of local governments in Tanzania as provided under article 145 of the constitution of the United Republic of Tanzania of 1977 is to relocate the authority of planning and implementation of the development programs to the people. Therefore in the local government councils, the Ward Officers such as Ward Education Officer, Ward Health Officer and Ward Development Officer form the operational personnel that foresee good governance at the Ward level (Mzee, 2018).

One among the objectives of the local government establishment was to facilitate development and democracy in the country. Local governments exist under section 145 of the constitution of the United Republic of Tanzania (Mzee, 2018) and have autonomy and mandate to exercise powers such as to raise revenue and plan to allocate resources under guiding laws. Wards are parts of Local governments that are under Ward Executive Officers (Mutahaba, 2012). These personnel oversee all government activities at that level. However, there are no evidence of assessment documents and evaluations done specifically for Arusha City and therefore it is not easy to establish challenges of leadership and governance at this level. Many people complain about the quality of services delivered at Ward level by Ward Officers (Ali, 2017). These circumstances lead to poor operations in Wards. Therefore the study sought to establish challenges faced by WOs in practicing accountability and participation in the Wards at ACC.

\section{Literature Review}

\section{Theoretical Review}

This study was guided by the good governance theory, introduced by the World Bank in 1992 after its publication titled "Good Governance and Development" (Ekundayo, 2017). The main principles of the good governance theory include participation which is an essential element of good governance theory that brings about the involvement of all adults in the politics prevailing in her the society through direct participation by individual citizens or through indirect participation through recognized representatives (Lateef, 2016). In addition, Good governance theory establishes principles that pledge equity, fairness along with justice in the society. Good governance theory insists on inclusive entrenchment of individual and group rights and unbiased adherence of the laws, which in turn call for an independent judiciary as well as an impartial and morally upright Police Force (IFAC, 2013). The rule of law also emphasizes that it is the law that rules, not man. Therefore, the laws of the land should be fair, impartial and no respecter of anybody (Lateef, 2016).

Good governance theory emphasizes that there must be transparency in the process of decisionmaking such that the ultimate decisions reached as well as the observance of such decisions must be carried out in compliance with rules and regulations. The transparency principle stipulates that sufficient information must be freely disseminated through an approach and medium that can be easily understood, and should be directly to the people that will be affected and who will ensure observance (Lateef, 2016; Ekundayo, 2017). In addition, the Good governance theory emphasizes responsiveness which concerns capacity as well as flexibility of the government to handle along with accommodating societal change (IFAC, 2013).

Furthermore, good governance practice requires consensus orientation; coalition building along with mediation among the diverse interests in addition to social forces in society in order to have a common agreement as far as a country's overall interest can be defined and achieved (IFAC, 2013). Equity and inclusiveness is a principle emphasized by the Good governance theory that guarantees dignity of a person, equal rights along with freedom from any discrimination (Lateef, 2016). The Good governance theory also emphasizes on principles of effectiveness which is primarily the process of doing right things, efficiency which is primarily the process of doing things right (Cole \& Kelly, 2011), and accountability which emphasizes that all actors, particularly those in government, business, 
voluntary agencies, civil-societies, among others are to be made answerable to the society (Raymond, 2015).

\section{Empirical Literature \\ Challenge in Practicing Good Governance}

Daniel, Adeola and Nchekwub (2014) employed the case study design and used secondary data to examine the challenges of good governance, accountability of governmental agencies and development in Nigeria. The findings revealed that manifestation of unethical behaviors amongst public officials is the major challenge hindering good governance in the country. Anowar (2014) conducted a study on governance and good governance related issues and sustainable development in Bangladesh. An explanatory design was used as well as extensive literature review and other secondary sources. It was discovered that democracy and governance in both public and private institutions in Bangladesh are still plagued with violence, corruption, outdated policies, human rights abuse, absence of rule of law, nonaccountability and heavy politicization of all government institutions including the judiciary.

Ntalaja (2011) conducted a study and applied descriptive and inferential statistics to examine the role of good governance in improving revenue collections in the delivery of public services in South Africa. The study established that public service delivery in Africa is slowed down by various factors such as corruption, staff incompetence, absence of good governance structures as well as lack of transparent revenue collection systems. Asiimwe and Steyn (2013) assessed factors hindering the effective governance of public universities in Uganda. The study revealed that the key obstacles to public university governance in the country were internal politics, lack of commitment, bureaucracy in management, conflicting values and cultures in the institutions, centralization of authority and decision-making procedures, inadequate funding and insufficient remuneration. Ali (2017) deployed qualitative research design to find out the role of good governance practices in enhancing service delivery in public institutions in Tanzania using the Tanzania Electric Supply Company (TANESCO) as a case. The study established that bureaucracy, corruption and delays were main factors that held back good governance initiatives at the TANESCO.
Literature about good governance and challenges in practicing good governance was reviewed from different parts of the world and Tanzania in particular (Asiimwe \& Steyn, 2013; Ntalaja, 2011; Wakasangula, 2017). These studies have described the importance of good governance in general, but none has evaluated good governance practices by Ward Officers as part of local government authorities. Thus, this study was conducted in Arusha City - Tanzania to establish good governance practices by Ward Officer.

\section{Research Methodology}

\section{Research Design}

The study adopted the descriptive research design and used the mixed method research approach.

\section{Population and Sampling}

Target population for the study included Ward Executive Officers, Ward Education Officers, Ward Development Officers, Ward Agricultural and Fishing Officers, Ward Health Officers, Ward Security /Police Officers and Ward Councilors. Sample was drawn from a total target population of 175 officers in 25 wards in Arusha City. The target population was chosen because the persons had rich data to expound the phenomenon of good governance practices being investigated. The researchers randomly selected 10 wards with a total of 72 officers. As informed by Yamane in 1967 in computing sample size from a finite population, the sample of 72 study participants was found appropriate for this study.

\section{Instruments}

This study used two (2) research instruments for data collection namely; questionnaires and interview guide. The researchers used this combination of methods for data collection because the use of more than one instruments helps to obtain adequate and relevant information for a study (Kothari, 2011). Questionnaires were distributed to ten (10) Ward Education Officers, ten (10) Ward Development Officers, ten (10) Ward Agricultural and Fishing Officers, ten (10) Ward Health Officers and ten (10) Ward Security /Police Officers at each of the selected ward. The Researchers preferred to use questionnaires because it can be administered to a large group of individuals at the same time and respondents are free to express their views without being intimidated by the researchers. However, only 68 respondents were able to respond accordingly. 
Furthermore, the researchers conducted a face-toface interview with ten (10) Ward Executive Officers (WEOs) and ten (10) Ward Councilors (WC) in the 10 selected wards. The focus was to gain an understanding of the WEOs and WCs regarding good governance practices at local government level. The use of interview enabled the researchers to explore responses from the individual persons and ask additional questions.

\section{Statistical Treatment of Data}

Quantitative data from closed end items in the questionnaire were analysed with the aid of the SPSS version 20 program for descriptive statistics and the results were presented in tables. The recorded interview discussions and responses from open-ended items were transcribed and analysed in a descriptive form. This means reading through the transcripts, identifying emerging themes and reoccurring ideas, which were coded.

\section{Validity and Reliability}

The study instruments were refined through the comments from research experts from the Institute of Accountancy Arusha, the research supervisor and fellow students. The expert opinions were used to make necessary corrections on the instruments to ensure its validity. The purpose was to make the instruments focused in capturing required information from respondents.

Cronbach's Alpha was used to measure the reliability or internal consistence of the Likert type items using the pilot study for the Wards not selected for the actual research purpose. The data obtained were analyzed using the SPSS program version 20 . The reliability test was done through split half method to obtain the reliability correlation coefficient. It was found that the overall reliability statistics on reliability correlation coefficient for questionnaire items was 0.88 . Reliability coefficient is considered acceptable if it is from 0.7 to 0.9 (Creswell \& Creswell, 2018). Hence, the instruments were considered reliable enough and thus, the researchers used them for field data collection.

\section{Ethical Consideration}

The researchers observed ethical issues such as avoiding plagiarism, obtained research permit before data collection and informed consent from respondents to participate in the study. The study ensured confidentiality to all respondents as well.

\section{Results and Discussion Challenges Faced By Ward Officers}

The study aimed to establish challenges faced by WOs in practicing accountability and participation in the Wards. To fulfil this objective, the study prepared items $\mathrm{C} 1$ to $\mathrm{C} 10$ in the questionnaire guide for respondents to fill. In filling the questionnaires, respondents were to put a tick to indicate their level of agreement or disagreement in each item. The questionnaire was prepared having five point Likert scale ranging from strongly agreed (5) to strongly disagreed (1). Mean and Standard Deviation were used to determine the average of responses (Creswell \& Creswell (2018).

Table 1: Challenges Faced by Ward Officers

\begin{tabular}{lllll}
\hline SN & \multicolumn{1}{c}{ Challenges } & Mean & Std. Dev & Remarks \\
\hline C1 & Citizens have little turn up in election of their political leaders & 4.69 & 0.468 & Agreed \\
C2 & Lack of community interests in decision making participation & 3.38 & 0.629 & Disagreed \\
C3 & Failure to say anything in the process of making decisions & 3.92 & 1.007 & Agreed \\
C4 & Lack of general agreement for development plans & 4.15 & 0.714 & Agreed \\
C5 & Diseases and illiteracy among residents & 3.98 & 1.178 & Agreed \\
C6 & Misuse of resources and pollution of environment & 3.69 & 1.17 & Agreed \\
C7 & There is Lack or insufficient of funds & 4.13 & 0.761 & Agreed \\
C8 & Services are not delivered on time & 3.23 & 1.325 & Disagreed \\
C9 & Bureaucracy and poor in management & 2.56 & 1.236 & Disagreed \\
C10 & Conflicting values and cultures & 3.46 & 1.22 & Agreed \\
\hline
\end{tabular}

The Remark was reached upon the mean value, whereby a mean value from $1.00-3.40$ was considered disagreed while the mean value from 3.41 - 5.00 was considered Agreed. Thus, challenges faced by WOs in practicing accountability and participation in the Wards to ensure good governance were analyzed based on the responses as presented in Table 1.
Findings in Table 1 show that respondents in their majority agreed with items C1, C3, C4, C5, C6, C7 and $\mathrm{C} 10$ as challenges faced by WOs in practicing accountability and participation. Findings revealed that, the major challenges were; Citizens in wards having little turn up in election of their political leaders ( $M=4.69 \mathrm{SD}=0.468)$, and adult citizens mostly not wanting to say anything in the process 
of making decisions ( $M=3.92 \quad S D=1.007)$. Furthermore, it was found that; there is lack of general agreement for development plans by all civil representatives $(M=4.15 S D=0.714)$, diseases and illiteracy among residents $(M=3.98 \mathrm{SD}=1.178)$, misuse of resources and pollutions of environment $(M=3.69 S D=1.17)$, lack or insufficient of funds $(M=4.13 \quad S D=0.761)$ and conflicting values and cultures $(M=3.46 \mathrm{SD}=1.22)$ as challenges faced by WOs in practicing accountability and participation.

These findings are supported by those of Rashid (2016) in Malaysia who concluded that there were poor quality customer service among employees, government agencies lacked sufficient resources and had a leadership that does not adequately involve its stakeholders in decision making, which led to customer dissatisfaction with the services provided in public institutions. The findings are also supported by those reported by Asiimwe and Steyn (2013) who assessed factors hindering the effective governance of public universities in Uganda and revealed that conflicting values and cultures in the institution, and inadequate funding are among key obstacles to public universities governance in Uganda.

In contrary, findings in Table 1 show that respondents disagreed with items $\mathrm{C} 2, \mathrm{C} 8$ and $\mathrm{C} 9$ to be the challenges faced by WOs in practicing accountability and participation. Findings revealed that, Lack of community interests in effective participation in decision making ( $M=3.38$ $S D=0.629)$, services not delivered on time $(M=3.23$ $\mathrm{SD}=1.325)$ and bureaucracy and poor in management $(M=2.56 \mathrm{SD}=1.236)$ were not among challenges faced by WOs in practicing accountability and participation. This means the mentioned factors are not part of challenge facing the WOs. These findings differ to those reported by Asiimwe and Steyn (2013) who assessed factors hindering the effective governance of public universities in Uganda and revealed that bureaucracy in management is one of the key obstacles to public university governance in the country.

On the side of Ward Executive Officers (WEOs) and Ward Councillors (WCs) who responded to interview, the study prepared a question which asked participants; "As a ward officer, what challenges do you face when practicing accountability and participation your Ward?"
Data from respondents were thematically analyzed and the findings indicate that the Ward Executive Officers (WEOs) and the Ward Councillors (WCs) had wide-ranging opinions on challenges faced in practicing accountability and participation in their Wards. Findings revealed that the major challenges faced when practicing accountability and participation included; the rigid nature of people and community not wanting to be involved in planning for their own developments $(11,55.0 \%)$ as well as poor participation of residents in election of their leaders and involvement in decision making (8, 40.0\%). One WC narrated:

There are many challenges you know, but the main ones worth mentioning are the rigid nature of people we have, they don't want to be involved in planning for their own developments. And as you know... participation requires people to be involved in decision making, the problem I face in that aspect is that, majority of residents do not show up in election of their leaders.

Other challenges include the presence of different and conflicting values and cultures (7, 35.0\%), presence of corruption within wards (8, 40.0\%) and lack of community awareness on their right to participation (8, 40.0\%). One respondent, for instance, argued that:

As Ward leaders in the City of Arusha, the presence of different and conflicting values and cultures is a great challenge to ensure accountability and participation. There is also a lack of awareness on the side of residents' rights to decision making. Also let us be honest that there is corruption within Wards which hinders participation of the community.

\section{Conclusions and Recommendations}

\section{Conclusions}

The study concludes that major challenges faced by WOs in practicing accountability and participation in their Wards include: little turn up of citizens in electing political leaders, adult citizens not wanting to say anything in the process of making decisions, lack of general agreement for development plans by civil representatives as well as diseases and illiteracy among residents. Other challenges faced by WOs are misuse of resources and environmental pollutions, lack or insufficient 
of funds and conflicting values and cultures. It is thus concluded that there is lack of transparency and accountability by Wards officer in the study area.

\section{Recommendations}

The following recommendations were given based on findings:

1. Local Government Authorities such as Wards and the Council should create awareness to the people on the importance of participating in different development activities from planning to implementation of those activities. This can inculcate a sense of ownership and belongingness to the community of the respective Wards.

2. There is a need for local government authorities to ensure that people are provided with civic education and are educated about the importance of participation and selection of their leaders in a democratic and transparent manner.

3. Ward Officers should make due attention in making available Ward information by ensuring they are accessible by the public. The practice of accountability and participation can be enhanced through collaborative and deliberate action of both village members and ward leaders.

4. Challenges indicated in this study would be addressed through collaborative and deliberate action of both village members and ward leaders.

\section{References}

Ali, S. A., 2017. The Role of Good Governance Practices in Enhancing Service Delivery in Public Institutions in Tanzania: The Case Study of the Tanzania Electric Supply Company Ltd, Dar Es Salaam: Open University of Tanzania.

Anowar, H. D., 2014. Impact of Good Governance on Development in Bangladesh. Unpublished Master DissertationRoskilde University: Roskilde, Denmark.

Asiimwe, S. \& Steyn, G. M., 2013. Obstacles Hindering the Effective Governance of Universities in Uganda. Journal of Social Sciences, 14(1), pp. 17-27.

Cole, G. A. \& Kelly, P., 2011. Management: Theory and Practice. Singapore: Cengage Learning EMEA.
Creswell, J. W. \& Creswell, J. D., 2018. Research Designs: Qualitative, Quantitative and Mixed Methods Approaches. 5th Edition. Los Angeles: SAGE Publication, Inc.

Daniel, E., Adeola, I. \& Nchekwub, B., 2014. The Challenges of Good Governance, Accountability of Governmental Agencies and Development in Nigeria. Acta Universitatis Danubius Administration, 6(2), pp. 42-25.

Ekundayo, W. J., 2017. Good Governance Theory and the Quest for Good Governance in Nigeria. International Journal of Humanities and Social Science, 7(5), pp. $154-161$.

IFAC, 2013. Good Governance in the Public Sector - Consultation Draft for an International Framework: Consultation Draft. International Federation of Accountants (IFAC)., pp. 45-58.

Kilimwiko, L., 2020. Civic Competence Contains Corruption. Dar es Salaam: Current ePaper.

Kothari, P. C., 2011. Research Methodology: Methods and Techniques. New Delhi: Wiley Eastern limited.

Lateef, K. S., 2016. The Evolution of the World Bank's Thinking on Governance, s.l. World Bank.

Mdee, A. \& Thorley, L., 2016. Good Governance, Local Government, Accountability and Service Delivery in Tanzania: Exploring the Context for Creating a Local Governance Performance Index, Swindon, UK: ESRC.

Mutahaba, G., 2012. Achieving good governance and development in Tanzania: Is leadership the missing link?. ESRF Policy Brief, 8(2), p. $21-42$.

Mzee, M. M., 2018. Local Government in Tanzania: Does the Local Government Law in Tanzania provide Autonomy to Local Government, Western Cape: University of the Western Cape.

Ntalaja, N. G., 2011. Good Governance of Public Services, Rabat, Morocco: Paper prepared for State Institute. 
Rahman, K., 2019. Overview of corruption and anticorruption in Tanzania, Berlin: Transparency International.

Rashid, M. H., 2016. Measuring and Achieving Quality Customer Service: A Study on Public Sector in Malaysia. World Development, 22(12), pp. 1895-1907.

Raymond, A., 2015. Assessment of the Roles of Ward Executive Officers (WEOs) in
Accomplishing their day-to-day Activities: A theoretical and Practical Overview: The Case of Mbeya City Council., Unpublished Master Dissertation: Mzumbe University.

Wakasangula, E., 2017. The Influence of Leadership on Good Governance: The Case of Selected Villages in Rungwe and Babati District Councils in Tanzania, Morogoro: Mzumbe University. 